\title{
Cannabis and driving: Results from a general population survey
}

\author{
F.J. Alvarez *, I. Fierro, M.C. Del Río \\ Department of Pharmacology, Institute for Alcohol and Drug Studies, Faculty of Medicine, University of Valladolid, 47005 Valladolid, Spain \\ Received 17 October 2006; received in revised form 4 March 2007; accepted 14 March 2007 \\ Available online 12 July 2007
}

\begin{abstract}
The role of illicit drugs on driving, and particularly of cannabis and driving, is the object of increasing awareness. While there is increasing evidence of their effect on psychomotor performance and increased risk of involvement in traffic accidents, limited information is available concerning factors that can predict the likelihood of driving under the influence of cannabis. The present study aims to determine the past year prevalence of driving under the influence of cannabis, and of being a passenger in a vehicle driven by a person under the influence of cannabis, as well as to examine the correlations with a broad range of potential risk factors. A total of 2500 people, aged between 14 and 70 and living in Castille and Leon (Spain), were surveyed in 2004 with regard to their consumption of alcohol and illicit drugs. Among those who reported cannabis use in the previous year, further assessment was carried out. $15.7 \%$ of those surveyed reported cannabis consumption in the previous 12 months, of whom 9.7\% reported driving a vehicle under the influence of cannabis during this period, on average eight times. One out of five (19.9\%) reported being a passenger in a vehicle driven by a person under the influence of cannabis, on average five times in the previous 12 months. The predictors of driving under the influence of cannabis were the population size of community, the number of drugs consumed, reference to cannabis-related problems and to being a passenger in a vehicle driven by a person under the influence of alcohol. The data show that cannabis consumption and driving is common, and requires more attention from policy makers.
\end{abstract}

(C) 2007 Elsevier Ireland Ltd. All rights reserved.

Keywords: Cannabis; Driving; Drug of abuse; Epidemiology; Road traffic accident

\section{Introduction}

There is growing interest, even concern, in the part played by drugs in traffic accidents, and how to instigate adequate measures to reduce their incidence. The white paper on the European Transport Policy points out that one of the priorities for reducing road deaths (by 50\% in 2010) is to intervene in the field of drugged driving [1].

The use of illicit drugs, and particularly cannabis, by drivers is frequent as seen in population surveys, as well as in studies conducted with people injured or killed in traffic accidents. It has been estimated that the prevalence of cannabis varies from 3.3 to $10 \%$ in people injured, and from 2.2 to $8.4 \%$ in those deceased as a consequence of the traffic accident [2].

Cannabis impairs psychomotor performance, there being a dosage-effect relation [3]. Case-control studies [4-7] have shown a greater risk of traffic accident among those who drive

\footnotetext{
* Corresponding author. Tel.: +34 983 423077; fax: +34 983423022.

E-mail address: alvarez@med.uva.es (F.J. Alvarez).
}

under the influence of cannabis, there being a dose-effect relation [4]. The increased risk is greater if cannabis is used in conjunction with alcohol and/or other illicit drugs [5].

Earlier studies have shown that it is not infrequent for drivers to report driving under the influence of cannabis. It has been found that $1.9 \%$ of the population reported driving in the previous year within one hour of consuming cannabis [8], while frequent cannabis users are much more likely $(82 \%)$ to report such behavior [9].

Little information is available concerning factors that can predict the likelihood of driving under the influence of cannabis, and there is none concerning those factors that can predict being a passenger in a vehicle driven by a person under the influence of cannabis. Recent studies have shown that men $[10,11]$, males with prior traffic offences [11], more experienced drivers [10], those who report drink driving [10], frequency of drug use [12] and multiple drug use [13], those who believe that driving under the influence of cannabis does not increase accident risk [13], as well as those who were diagnosed as cannabis-dependent $[11,13]$, were more likely to report driving under the influence of cannabis. 
The present study aims to determine the past year prevalence of driving under the influence of cannabis, and of being a passenger in a vehicle driven by a person under the influence of cannabis, as well as to examine the correlations with a broad range of potential risk factors. This information would be very useful for the development of more effectively targeted drugged-driving prevention policies.

\section{Materials and methods}

\subsection{Population}

Non-institutionalized people between the ages of 14 and 70 years living in Castille and León, Spain were the target population, as previously described $[14,15]$. The face-to-face interviews for the survey were conducted in May 2004. Data were collected in personal interviews with people selected at random from a representative sample of Castille and Leon households. One hundred and ninety-five individuals refused to take part in the study. The interview was not fully completed in 25 cases. A final sample of 2,500 individuals was selected. The final response rate was of $91.9 \%$. The sample was taken from the population register data of 2001. The sample was stratified: first, according to the number of inhabitants in the community (population size of community); second, by province on the basis of the regional administrative division (9 provinces), leading to 98 field interview areas; third, by age groups; and fourth, by gender.

The sample distribution ( $n=2500)$ was as follows: (i) gender: males $=1266$ $(50.6 \%)$ and females $=1234(49.4 \%)$; (ii) age group: $14-19$ years $=222(8.9 \%)$, $20-29$ years $=491(19.6 \%), 30-39$ years $=509(20.4 \%), 40-49$ years $=471$ $(18.8 \%), 50-59$ years $=392(15.7 \%), 60-70$ years $=415(16.6 \%)$. The sociodemographic variables recorded, apart from gender, age, and population size of community, included civil status, education level, and occupational status $[14,15]$.

\subsection{Measures}

The following potential predictor variables were explored: socio-demographic aspects (age, population size of community, civil status, education level, occupational status), patterns of cannabis use and related problems (starting age on cannabis consumption, number of drugs consumed in the previous year, perceived risk of cannabis consumption on health, reporting cannabis-related problem in the previous year) and patterns of alcohol consumption (frequency of drinking, drinking level, CAGE 2 or more scores, driving under the influence of alcohol in the previous year, being a passenger in a vehicle driven by a person under the influence of alcohol in the previous year). The outcomes were: (i) report of driving under the influence of cannabis in the previous 12 months and, (ii) being a passenger in a vehicle driven by a person under the influence of cannabis in the previous 12 months.

The analysis was done on those surveyed that reported cannabis consumption in the previous year.

\subsection{Cannabis use}

Those surveyed were asked if they had consumed cannabis in the year prior to the survey and the starting age of cannabis consumption, if they have consumed cannabis. Number of drugs consumed in the previous year was recorded, including the consumption of drugs other than cannabis in the previous year (opiates, cocaine, amphetamines, designer drugs, inhalants, hallucinogenic drugs, non-medical use of tranquillizers) was recorded, as well as being weekly drinkers (see next section). The number of drugs consumed was categorized as 1 (only cannabis), 2 (cannabis plus another drug or being a weekly drinker) or 3 or more (cannabis plus other drugs or other drug(s) and being weekly drinker).

Perceived risk of cannabis consumption on health: The opinion of those surveyed regarding the health consequences of regular cannabis use was recorded. Allowed responses were "very high", "quite high", "not very high" and "not high at all".
Cannabis-use related problems: Participants were also asked, "have you, at any time during the past year, had any of the following problems as a consequence of the consumption of cannabis" (i) Work accidents or other problem requiring urgent medical attention; (ii) Arrest by the police or forces of public order; (iii) Absence from work (or school) for one or more days; (iv) Argument, discussion, or serious conflict without physical aggression; (v) Fight or physical aggression. Whether or not those surveyed reported any of these problems in the previous year was also recorded.

Report of past year driving under the influence of cannabis, and the number of days this was done, by those who reported cannabis use in the previous year.

Past year being a passenger in a vehicle driven by a person under the influence of cannabis, and the number of days this was done, by those who reported cannabis use in the previous year.

\subsection{Alcohol use}

Frequency of drinking: Current drinkers were those who have had at least one drink in the past year. Current drinkers were split into weekly and occasional drinkers. Weekly drinkers were those who had drunk alcohol at least once a week over the preceding year. Occasional drinkers were those who had drunk alcohol less than once a week over the preceding year [14].

Drinking level: The survey assessed drinkers for consumption level. Drinkers were classified based on their consumption level as follows: Low consumption: men $\leq 21$ units/week and women $\leq 14$ units/week; moderate consumption: men 22-50 units/week and women 15-35 units/week; high consumption: men $>50$ units/week and women $>35$ units/week [14].

The CAGE questionnaire [16], in the Spanish validated version [17], was used in current drinkers. CAGE scores of two or more (problem drinker), were those that reported a positive answer to two or more of the CAGE questions [14].

Report of past year driving under the influence of alcohol, and the number of days this was done, by those who reported alcohol use (current drinkers) in the previous year.

Past year being a passenger in a vehicle driven by a person under the influence of alcohol, and the number of days this was done, by those who reported alcohol use in the previous year.

\subsection{Statistical analysis}

The statistical analysis was performed using SPSS version 13.0. This included the chi-square test, and $t$-test when appropriate. In order to evaluate the possible interaction between independent variables (age, population size of community, civil status, education level, occupational status, starting age on cannabis consumption, number of drugs consumed in the previous year, perceived risk of cannabis consumption on health, reporting cannabis-related problem in the previous year, alcohol use, drinking level, CAGE 2 or more scores, driving under the influence of alcohol, being a passenger in a vehicle driven by a person under the influence of alcohol in the previous year) a logistic regression analysis was carried out in which the variable effect was a report of past year driving under the influence of cannabis or past year being a passenger in a vehicle driven by a person under the influence of cannabis. The logistic regression method was used: forward step with an input probability of 0.05 and an output probability of 0.10 . odds ratio (OR) was established at $95 \%$ confidence interval (CI). A $P$-value of $\leq 0.05$ was considered statistically significant.

\section{Results}

\subsection{Patterns of cannabis use}

$15.7 \%(n=392)$ of those surveyed reported cannabis consumption in the previous 12 months $(19.9 \%-(n=252)$ males; $11.3 \%-(n=140)$ - females, $\left.\chi^{2}=34.632, p<0.005\right)$. This study focused on these consumers of cannabis in the year prior to carrying out the survey. 
The initiation age for consuming cannabis was $17.4 \pm 2.9$ years (mean \pm S.D., Table 1 ). $24.2 \%$ have only consumed cannabis in the previous year, while $52.6 \%$ had consumed both cannabis and other drug $(4.8 \%$ had consumed two illegal drugs, and $47.8 \%$ had consumed cannabis and were weekly drinkers), and $23.2 \%$ had consumed at least three or more drugs in the previous year (Table 1). The most frequently consumed drugs in the year prior to the survey of cannabis users were: cocaine $(16.6 \%$ for the total, $18.3 \%$ of men and $13.6 \%$ of women, $\left.\chi^{2}=1.427, p>0.05\right)$ and synthetic drugs $(10.5 \%$ for the total, $9.5 \%$ of males and $12.2 \%$ of females, $\left.\chi^{2}=0.699, p>0.05\right)$. $11.0 \%$ of cannabis consumers admitted suffering from cannabis-related problems in the previous year. $36.7 \%$ considered the regular consumption of cannabis to be little to no risk to health, while $63.3 \%$ considered it to be fairly or very risky. No differences were observed between sexes in the patterns of drug consumption ( $p>0.05$, Table 1$)$, except for a smaller perception of the health risk among men as opposed to women $(p<0.01$, Table 1$)$.

Alcohol consumption is frequent among cannabis consumers: $68.8 \%$ are weekly drinkers, $40.8 \%$ with a low consumption, while $28 \%$ have a moderate or high alcohol consumption, and $12.5 \%$ had two or more scores in the CAGE test. In the previous year, $11.7 \%$ reported driving a vehicle under the influence of alcohol and $21.9 \%$ reported being a passenger in a vehicle driven by a person under the influence of alcohol. In no case were differences found between sexes ( $p>0.05$, Table 1), except that more men than women reported driving a vehicle under the influence of alcohol $(p<0.01$, Table 1$)$.

\subsection{Driving under the influence of cannabis}

Of those surveyed that reported cannabis consumption in the previous year, $9.7 \%$ (10.7\% of males, $7.9 \%$ of females, $\left.\chi^{2}=0.818, p>0.05\right)$ reported driving a vehicle under the influence of cannabis during this period, on average (mean \pm S.D.) $8.1 \pm 18.7$ times $(10.6 \pm 21.7$ for males and $2.2 \pm 2.3$ for females, $t=1.253, p>0.05)$. Fig. 1 shows the age-related distribution: those aged 20-29 most frequently reported driving under the influence of cannabis, and by a higher number of days. Having a road traffic accident while being under the influence of cannabis was reported by 6 out of 32 past year cannabis users that reported driving under the influence of cannabis, 3 males and 3 females $\left(\chi^{2}=0.549\right.$, $p>0.05)$.

Logistic regression analysis (Table 2) showed that: population size of community $(\mathrm{OR}=1.53$; the lower the population size, the higher the likelihood), those who refer to

Table 1

Frequency of predictor variables in past year cannabis users

\begin{tabular}{|c|c|c|c|}
\hline Predictor variables & Total $(n=392)(\%)$ & Male $(n=252)(\%)$ & Female $(n=140)(\%)$ \\
\hline $\begin{array}{l}\text { Starting age of cannabis consumption (mean } \pm \text { S.D.) } \\
\quad(t=-1.723, p>0.05)\end{array}$ & $17.4 \pm 2.9$ & $17.3 \pm 3.1$ & $17.8 \pm 2.5$ \\
\hline \multicolumn{4}{|l|}{ Number of drugs consumed in the previous year } \\
\hline 1 & 24.2 & 22.2 & 27.9 \\
\hline 2 & 52.6 & 53.6 & 50.7 \\
\hline $\begin{array}{c}3 \text { or more } \\
\left(\chi_{2}^{2}=1.618, p>0.05\right)\end{array}$ & 23.2 & 24.2 & 21.4 \\
\hline \multicolumn{4}{|l|}{ Perceived risk of cannabis consumption on health } \\
\hline Very high/quite high & 63.3 & 57.5 & 73.6 \\
\hline $\begin{array}{l}\text { Not very high/not high at all } \\
\left(\chi^{2}=9.953, p<0.005\right)\end{array}$ & 36.7 & 42.5 & 26.4 \\
\hline $\begin{array}{l}\text { Reporting cannabis-use related problems } \\
\left(\chi^{2}=0.632, p>0.05\right)\end{array}$ & 11.0 & 11.9 & 9.3 \\
\hline \multicolumn{4}{|l|}{ Frequency of alcohol consumption } \\
\hline Non drinker & 5.4 & 6.0 & 4.3 \\
\hline Occasional drinker & 25.8 & 24.2 & 28.6 \\
\hline $\begin{array}{l}\text { Weekly drinker } \\
\left(\chi_{3}^{2}=1.227, p>0.05\right)\end{array}$ & 68.8 & 69.8 & 67.1 \\
\hline \multicolumn{4}{|l|}{ Drinking level } \\
\hline Non drinker & 31.1 & 30.2 & 32.9 \\
\hline Low consumption & 40.8 & 42.9 & 37.1 \\
\hline Moderate consumption & 20.9 & 20.2 & 22.1 \\
\hline $\begin{array}{l}\text { High consumption } \\
\left(\chi_{3}^{2}=1.242, p>0.05\right)\end{array}$ & 7.1 & 6.7 & 7.9 \\
\hline 2 or more CAGE scores $\left(\chi^{2}=0.025, p>0.05\right)$ & 12.5 & 12.7 & 12.1 \\
\hline Driving under the influence of alcohol $\left(\chi^{2}=7.621, p<0.01\right)$ & 11.7 & 15.1 & 5.7 \\
\hline $\begin{array}{l}\text { Being a passenger in a vehicle driven by a person under the } \\
\text { influence of cannabis }\left(\chi^{2}=0.033, p>0.05\right)\end{array}$ & 21.9 & 22.2 & 21.4 \\
\hline
\end{tabular}


cannabis-related problems in the previous year $(\mathrm{OR}=2.86)$, those who refer to being a passenger in a vehicle driven by a person under the influence of alcohol in the previous year $(\mathrm{OR}=2.84)$ and the number of drugs consumed $(\mathrm{OR}=1.80$, the higher the number of drugs consumed, the higher the likelihood), all have a predisposing influence on reporting driving under the influence of cannabis in the previous year. None of the other tested independent variables showed a significant effect $(p>0.05)$.

\subsection{Being a passenger in a vehicle driven by a person under the influence of cannabis}

One out of five (19.9\% for the total, $19.4 \%$ of males, $20.7 \%$ of females, $\left.\chi^{2}=0.103, p>0.05\right)$ of those who had consumed cannabis in the previous year, reported being a passenger in a vehicle driven by a person under the influence of cannabis in this period, on average (mean \pm S.D.) $5.7 \pm 9.0$ times $(7.1 \pm 11.0$ for males and $3.3 \pm 2.2$ for females, $t=1.820$, $\mathrm{p}>0.05)$. Fig. 1 shows the age-related distribution: those aged 14-19 most frequently reported being a passenger in a vehicle driven by a person under the influence of cannabis, and by a higher number of days.

Logistic regression analysis (Table 3) showed that: age ( $\mathrm{OR}=0.93$; the older, the lower the likelihood), those who refer to having a paid job $(\mathrm{OR}=2.20)$, starting age of cannabis consumption ( $\mathrm{OR}=0.88$, the later the starting age, the lower the likelihood) and those who refer to being a passenger in a vehicle driven by a person under the influence of alcohol in the previous year $(\mathrm{OR}=3.16)$, all have a predisposing influence on being a passenger in a vehicle driven by a person under the influence of cannabis. None of the other tested independent variables showed a significant effect $(p>0.05)$.

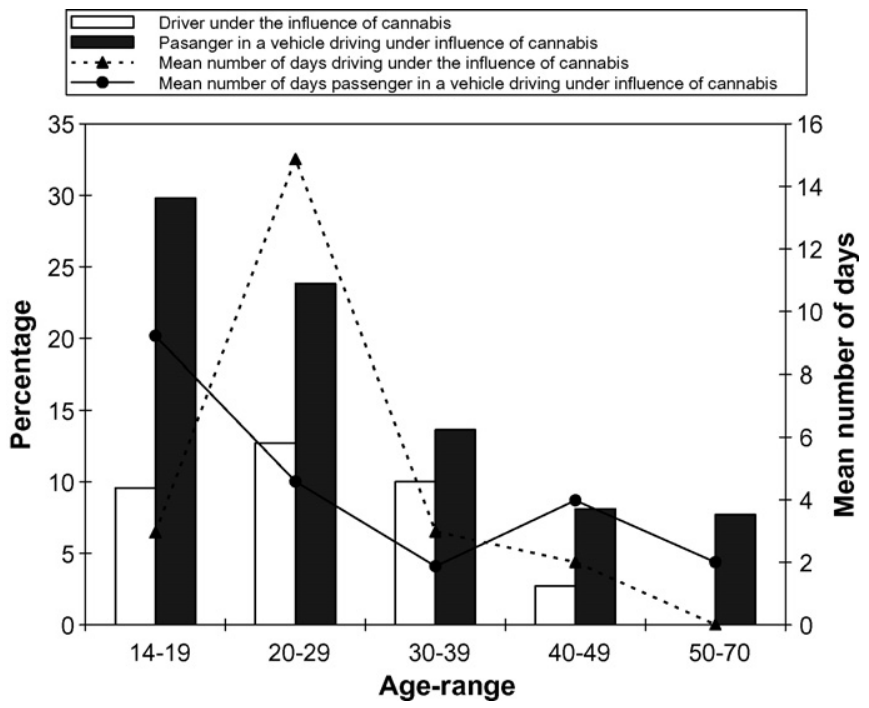

Fig. 1. Age-related distribution of frequency and mean number of days of driving under the influence of cannabis and being a passenger in a vehicle driven by a person under the influence of cannabis.
Table 2

Significance level, odds ratio (OR), 95\% confidence interval (CI) for variables that predict driving under the influence of cannabis

\begin{tabular}{llll}
\hline & $P$-value & OR & $95(\%) \mathrm{CI}$ \\
\hline $\begin{array}{l}\text { Population size of community } \\
\begin{array}{c}\text { Reference to cannabis-related } \\
\text { problem in the previous year }\end{array}\end{array}$ & $<0.005$ & 1.53 & $1.16-2.01$ \\
$\begin{array}{l}\text { Being a passenger in a vehicle } \\
\text { driven by a person under the } \\
\text { influence of alcohol }\end{array}$ & $<0.05$ & 2.86 & $1.19-6.86$ \\
$\begin{array}{l}\text { Number of drugs consumed in } \\
\text { the previous year }\end{array}$ & $<0.05$ & 2.84 & $1.29-6.27$ \\
\hline
\end{tabular}

\section{Discussion}

The present study shows that driving under the influence of cannabis and being a passenger in a vehicle driven by a person under the influence of cannabis, are frequent behaviors: these were reported by 9.7 and $19.9 \%$, respectively, of past year cannabis users. For the total population, these figures represent 1.5 and $3.1 \%$, respectively. Furthermore, individuals that report such behaviors do it several times in the previous year (on average 8.1 and 5.7 times, respectively). The figure for driving under the influence of cannabis was relatively lower than that reported previously by Walsh and Mann [8] of $1.9 \%$ for the Canadian population. A much higher figure was reported by regular cannabis users (use $>$ monthly, 82\%)[9].

We have found that there are no gender differences in either behavior, unlike previous studies [10,11]. Driving under the influence of cannabis occurs more frequently and by a higher number of times in those aged 20-29, while being a passenger in a vehicle driven by a person under the influence of cannabis occurs more frequently in those aged 14-19, and decreases with age. In the latter case, it is easy to understand that the lack of a driving license (in Spain the authorized age for holding a driver license is 18 years of age) could explain the high figure for this age group. However, it is also worth mentioning that high percentages were observed in all age-ranges. While data of driving under the influence of cannabis are reliable - as those surveyed were asked explicitly for this behavior - knowing that the driver is under the influence of cannabis could be based, in some cases, on suspicions rather than on real facts, by those surveyed. Therefore this should be viewed with caution.

Table 3

Significance level, odds ratio (OR), 95\% confidence interval (CI) for variables that predict being a passenger in a vehicle driven by a person under the influence of cannabis

\begin{tabular}{llll}
\hline & $P$-value & OR & $95(\%) \mathrm{CI}$ \\
\hline Age & $<0.001$ & 0.93 & $0.89-0.97$ \\
With paid employment & $<0.05$ & 2.21 & $1.16-4.19$ \\
Starting age to cannabis & $<0.05$ & 0.88 & $0.78-0.99$ \\
$\quad$ consumption & & & \\
$\begin{array}{l}\text { Being a passenger in a } \\
\quad \text { vehicle driven by a }\end{array}$ & $<0.0001$ & 3.16 & $1.80-5.55$ \\
$\quad$ person under the & & & \\
$\quad$ influence of alcohol & & & \\
\hline
\end{tabular}


Logistic regression analysis showed different characteristics were associated with these behaviors, except for references to being a passenger in a vehicle driven by a person under the influence of alcohol in the previous year, that was associated with both behaviors. Reporting driving under the influence of cannabis was also more common the higher the number of drugs consumed, and the number of references to cannabis-related problems. In previous studies, frequency of cannabis use [12], multiple drug use [13] and having a diagnosis of cannabis-dependence $[11,13]$ was associated with driving under the influence of cannabis. Finally, we have found that the lower the population size where those surveyed live, the higher the likelihood of driving under the influence of cannabis.

Being a passenger in a vehicle driven by a person under the influence of cannabis was less likely the later the age of starting cannabis smoking and the older they are, while it was more likely in those that refer to having a paid job.

The present data show that driving under the influence of cannabis is frequent. As with earlier data from our country in which frequent consumption of drugs among drivers [18], and particularly of cannabis was shown, as well as a frequent detection of cannabis in drivers killed in road traffic accidents [19], cannabis and driving is a real problem that needs the development of appropriate countermeasures. Recent reports of a noticeable increase of cannabis, cocaine and amphetamine consumption among young French drivers killed in traffic accidents add to the urgency [20]

The development of a reliable system to detect drugs/ cannabis in oral fluid $[21,22]$ and the establishment of cut-offs based on scientific data [23-25], could allow the development of appropriate legislative and enforcement measures [26]. It has also been reported that increasing the certainty of punishment would reduce driving under the influence of cannabis, while providing information about the risk associated with such behavior has little effect [27].

\section{Conclusion}

The present data show that cannabis consumption and driving is a relevant issue that needs much more attention: an important part of the population is driving under the influence of cannabis, while being a passenger in a vehicle driven by a person under the influence of cannabis is even more frequently reported. The development of appropriate policies is then encouraged.

\section{Acknowledgements}

This work has been supported by grants from the Consejería de Familia e Igualdad de Oportunidades, and from the Ministerio de Sanidad y Consumo, Redes Temáticas de Investigación Cooperativa, Red de Trastornos Adictivos RD06/0001/0020.

\section{References}

[1] European Commission, White Paper European Transport Policy for 2010: time to decide, Office for Official Publications of the European Communities, Luxembourg, 2001.

[2] E. Raes, A. Verstraete, Cannabis et conduite automobile: la situation en Europe, Ann. Pharm. Fr. 64 (2006) 197-203.

[3] J.G. Ramaekers, G. Berghaus, M. Van Laar, O.H. Drummer, Dose related risk of motor vehicle crashes after cannabis use, Drug Alcohol Depend. 73 (2004) 109-111.

[4] B. Laumon, B. Gadegbeku, J.L. Martin, M.B. Biecheler, Cannabis intoxication and fatal road crashes in France: population based case-control study, Br. Med. J. 331 (2005) 1371-1376.

[5] O.H. Drummer, J. Gerastomoulos, H. Batziris, M. Chu, J. Caplehorn, M.D. Robertson, P. Swann, The involvement of drugs in drivers of motor vehicles killed in Australian road traffic crashes, Accid. Anal. Prev. 36 (2004) 239-248.

[6] P. Mura, P. Kintz, B. Ludes, J. Gaulier, P. Marquet, Comparison of the prevalence of alcohol, cannabis and other drugs between 900 injured drivers and 900 control subject: results of a French collaborative study, Forensic Sci. Int. 133 (2003) 79-83.

[7] S. Blows, R.Q. Ivers, J. Connor, S. Ameratunga, M. Wodward, R. Norton, Marijuana use and car crash injury, Addiction 100 (2005) 605-611.

[8] G.W. Walsh, R.E. Mann, On the high road: driving under the influence of cannabis in Ontario, Can. J. Public Health 90 (1999) 260-263.

[9] P. Terry, K.A. Wright, Self-reported driving behaviour and attitudes towards driving under the influence of cannabis among three different user groups in England, Addict. Behav. 30 (2005) 619-626.

[10] M. Asbridge, C. Poulin, A. Donato, Motor vehicle collision risk and driving under the influence of cannabis: evidence from adolescents in Atlantic Canada, Accid. Anal. Prev. 37 (2005) 1025-1034.

[11] D.J. Begg, J.D. Langley, S. Stephenson, Identifying factors that predict persistent driving after drinking, unsafe driving after drinking, and driving after using cannabis among young adults, Accid. Anal. Prev. 35 (2003) 669-675.

[12] B. Fischer, J. Rodopoulos, J. Rehm, A. Ivsins, Toking and driving: characteristics of Canadian university students who drive after cannabis use - and exploratory pilot study, Drugs Ed. Prev. Pol. 13 (2006) 179-187.

[13] C. Jones, W. Swift, N.J. Donnelly, D.J. Weatherburn, Correlates of driving under the influence of cannabis, Drug Alcohol Depend.

[14] J. Alvarez, I. Fierro, M.C. del Rio, Alcohol-related social consequences in Castille and Leon, Spain, Alcohol Clin. Exp. Res. 30 (2006) 656-664.

[15] F.J. Álvarez, I. Fierro, El consumo de drogas en Castilla y León, 2004, Consejería de Familia e Igualdad de Oportunidades, Valladolid, 2006.

[16] J.A. Ewing, Detecting alcoholism: the CAGE questionnaire, JAMA 252 (1984) 1905-1907.

[17] A. Rodríguez-Martos, R.M. Navarro, C. Vecino, R. Pérez, Validación de los cuestionarios KFA (CBA) y CAGE para el diagnóstico del alcoholismo, Drogalcohol 11 (1986) 132-139.

[18] F.J. Alvarez, M.C. del Río, Illegal drugs taking and driving: patterns of drug taking among Spanish drivers, Drug Alcohol Depend. 37 (1995) 83-86.

[19] M.C. del Rio, J. Gomez, M. Sancho, F.J. Alvarez, Alcohol, illicit drugs and medicinal drugs in fatally injured drivers in Spain between 1991 and 2000, Forensic Sci. Int. 127 (2002) 63-70.

[20] P. Mura, C. Chatelain, V. Dumestre, J.M. Gaulier, M.H. Ghysel, C. Lacroix, M.F. Kergueris, M. Lhermitte, M. Moulsma, G. Pepin, F. Vincent, P. Kintz, Use of drugs of abuse in less than 30-year-old drivers killed in a road crash in France: a spectacular increase for cannabis, cocaine and amphetamines, Forensic Sci. Int. 160 (2006) 168-172.

[21] A.G. Verstraete, Oral fluid testing for driving under the influence of drugs: history, recent progress and remaining challenges, Forensic Sci. Int. 150 (2005) 143-150.

[22] V. Cirimele, M. Villain, P. Mura, M. Bernard, P. Kintz, Oral fluid testing for cannabis: on-site OraLine IV s.a.t. device versus GC/MS, Forensic Sci. Int. 161 (2006) 180-184.

[23] J.G. Ramaekers, M.R. Moeller, P. van Ruitenbeek, E.L. Theunissen, E. Schneider, G. Kauert, Cognition and motor control as a function of 
Delta(9)-THC concentration in serum and oral fluid: limits of impairment, Drug Alcohol Depend. 85 (2006) 114-122.

[24] H.Z. Khiabani, J.G. Bramness, A. Bjorneboe, J. Morland, Relationship between THC concentration in blood and impairment in apprehended drivers, Traffic Inj. Prev. 7 (2006) 111-116.

[25] K. Papafotiou, J.D. Carter, C. Stough, The relationship between performance on the standardised field sobriety tests, driving performance and the level of Delta9-tetrahydrocannabinol (THC) in blood, Forensic Sci. Int. 155 (2005) 172-178.

[26] M. Asbridge, Drugs and driving: when science and policy don't mix, Can. J. Public Health 97 (2006) 283-285.

[27] C. Jones, N. Donnelly, W. Swift, D. Weatherburn, Preventing cannabis users from driving under the influence of cannabis, Accid. Anal. Prev. 38 (2006) 854-861. 